引用格式: 明雨佳, 刘勇, 周佳松. 基于大数据的山地城市活力评价: 以重庆主城区为例 [J]. 资源科学, 2020, 42(4): 710-722. [Ming Y J, Liu Y, Zhou J S. Vitality assessment of mountainous cities based on multi- source data: A case of Chongqing Municipality, China[J]. Resources Science, 2020, 42(4): 710-722.] DOI: 10.18402/resci.2020.04.10

\title{
基于大数据的山地城市活力评价 以重庆主城区为例
}

\author{
明雨佳 ${ }^{1}$, 刘 勇 ${ }^{1}$, 周佳松 ${ }^{2}$ \\ (1. 重庆大学管理科学与房地产学院, 重庆 400044; \\ 2. 四川省国土整治中心,成都 610000)
}

\begin{abstract}
摘 要: 在中国快速城市化进程中出现了大量的城市病, 导致城市品质下降和区域发展失衡。城市活力为研 究城市问题提供了一个新的视角, 而大数据的蓬勃发展为城市活力研究提供了准确高效的新手段。本文采用人口 热力、兴趣点(POI) 和街景活力感知 3 个指标构建评价体系, 对重庆主城的城市活力进行定量评价。结果发现: 重庆 主城区的城市活力分布呈现多中心的分布特征，与其“多中心、组团式”的城市结构相契合。3 个指标评价出的城市 活力在空间格局上具有相似性,城市活力高的区域主要分布在重庆内环内侧, 尤其是解放碑主中心及活力相对较 高的沙坪坝、杨家坪、观音桥、南坪副中心, 而外围活力高的区域对应茶园、西永等内环以外的副中心和城市组团, 这一结果与街景活力感知得分较为符合。研究认为, 基于大数据对重庆城市活力进行客观识别和评价, 为城市活 力定量研究提供了一种新的思路和视角, 弥补了传统定性分析方法的不足。针对山地城市的研究, 同时弥补了已 有文献在山地城市活力研究方面的不足,对空间规划有一定的参考价值
\end{abstract}

关键词: 城市活力; 热力图; POI; 街景活力感知; 重庆市

DOI :10.18402/resci.2020.04.10

\section{1 引言}

城市活力是城市空间旺盛生命力和城市功能 生存发展的保证 ${ }^{[1]}$, 一直是城市研究的热点之一。 目前, 中国正处于城市化快速发展阶段, 盲目、粗 放、忽略空间品质的城市扩张方式盛行, 导致交通 拥堵、城市品质下降以及区域发展失衡等问题 $[2,3]$ 。 构建 “以人为本、城乡统筹、绿色节约、宜居和谐” 的 城市发展模式, 深人推进新型城镇化及生态文明建 设已成为当前时代发展的新诉求 ${ }^{[4,5]}$ 。城市活力研 究能评价城市内部的活力现状 ${ }^{[6]}$, 有效检验城市空 间品质及分布特征 ${ }^{[7]}$, 为优化城镇布局和形态提供 了新的视角。

目前, 城市活力的定性研究已有较丰富的成
果,但尚未就城市活力形成统一的定义。雅各布最 先提出城市活力的概念: “人与人活动及生活场所 相互交织的过程,形成城市生活的多样性,使城市 获得了活力” ${ }^{[8]}$ 。林奇 ${ }^{[9]}$ 将城市的活力定义为: “一个 聚落形态对于生命的机能、生态的要求和人类需求 的支持程度”。丹麦学者盖尔 ${ }^{[10]}$ 指出: “城市公共空 间的活力在于处于其中的人以及人们的活动”。基 于文献梳理, 本文认为城市活力源于城市居民与城 市空间的互动性, 人是产生城市活力的主体和基 础, 空间是产生城市活力的必要条件。由人的聚集 与活动产生多样性的城市生活, 是城市旺盛生命力 的源泉。

定性研究多从城市活力的内涵、演变、特征以

收稿日期: 2019-11-04,修订日期: 2020-03-21

基金项目:国家自然科学基金项目(71974022;41771534)。

作者简介: 明雨佳,女,四川广元人, 硕士研究生, 主要研究方向为城市土地利用。E-mail: 278751286@qq.com 通讯作者: 刘勇, 男, 湖南岳阳人,博士, 副教授, 研究方向为城市地理学与土地利用。E-mail: 1y6505@163.com 
城市空间结构呈组团式发展已久,并不断强化形成

及构成要素等方面开展, 缺乏数据的支撑, 难以适 应当下复杂多变的城市形态。传统定量分析通常 基于问卷调查 ${ }^{[11]}$ 和专家打分 ${ }^{[12]}$ 等方式进行, 无法支 撑庞大城市系统研究的数据需求, 难以突破研究空 间规模的局限性 ${ }^{[13]}$ 。近年来, 大数据在各行各业蓬 勃发展, 对信息时代下的学术研究产生了重大的影 响。基于位置服务 (LBS) 社交网络、互联网兴趣点 (POI) 以及交通智能集成卡 (IC) 刷卡等数据开始广 泛运用于城市研究 ${ }^{[14,15]}$ 。部分学者开始尝试基于大 数据的城市活力研究, 主要从人的活动与城市空间 两个维度展开, 具体指标包括衡量人口活动强度的 人口聚集度、就业集中度、商业活动强度等及表征 城市空间的人口、设施、夜间灯光等常见城市要素 ${ }^{[16-18]}$, 但少有研究关注人的主观感受。街景活力感知作 为主观评价维度, 基于人与空间的主观联系对城市 活力进行评价, 更加强调人与空间的互动性。

虽然有关城市活力的研究文献不断累积, 上 海 ${ }^{[12]}$ 、成都 ${ }^{[18]}$ 、北京 ${ }^{[19]}$ 等平原城市已经取得了较多的 成果, 但山地城市活力的研究成果十分有限。与平 原城市相比, 山地城市复杂和多样性的空间结构, 为城市管理和规划带来了更大的挑战,对山地城市 的城市活力的探索亟需进行。基于此, 本文从客观 和主观两个角度出发, 构建城市活力的评价体系, 对重庆的城市活力进行定量评价, 希望可以弥补山 地城市活力研究的不足, 为城市活力定量研究提供 新的思路,为城市规划提供有价值的参考。

\section{2 研究区域、数据来源与研究方法}

\section{1 研究区域}

选择重庆主城区为研究对象, 涵盖渝中区、大 渡口区、江北区、南岸区、沙坪坝区、九龙坡区、北碚 区、渝北区、巴南区9个行政区。

作为西部地区唯一的直辖市、成渝都市圈的中 心城市, 重庆自西部大开发以来, 城市化发展较 快。主城区幅员面积 $5472.68 \mathrm{~km}^{2}, 2018$ 年常住人口 875 万人, 重庆市主城区的城镇化率 $90.51 \%$ 。作为 重庆市经济最发达的地区,2018年重庆主城区 GDP 总和 8208.39 亿元, 以占全市总面积不到 7\%的土地 贡献了全市 $40.30 \%$ 的 GDP。重庆主城区有大量的 人口以及相对集中和优越的公共资源, 容易产生大 规模的聚集,适合开展城市活力研究。

受地形起伏、江河阻隔、道路切割的影响, 重庆
“多中心、组团式”的城市空间结构。城市内部高度 异质的空间结构, 导致重庆城市活力具有显著的空 间差异性。在城市化进程中,持续的新区开发和旧 城改造, 影响城市的人口活动与资源分配 ${ }^{[20]}$, 导致城 市活力进一步差异化。因此重庆主城区是研究山 地城市的城市活力的典型区域。

\section{2 研究方法}

本文在参考已有研究的基础上, 从人的活动、 城市空间要素和人的主观感受 3 个维度构建评价体 系。通过 Python 程序抓取网络数据, 通过 ArcGIS工 具对数据进行处理,利用核密度分析、自然断点法、 最邻近分析等方法,识别城市活力在不同评价指标 下的空间分布特征。

\subsection{1 分析框架}

已有较多针对城市活力的研究表明人的活动 和城市功能设施与城市活力有着密切的正相关关

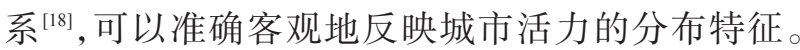
因此本文选择人的活动和城市空间要素作为 2 个客 观评价维度, 在此基础上进一步将人对街景的活力 感知作为城市活力的主观评价维度。基于 3 个维度 选择具体的测度指标, 对重庆主城区城市活力展开 评价。基于评价结果,选择 4 个典型案例,验证城市 活力的分布特征, 并讨论 POI 混合度和人口活动强 度对城市活力的影响(图 1)。

\subsection{2 指标选择}

本文在人的活动、城市空间要素和人的主观感 受 3 个维度下选择城市活力评价的具体指标。具体 包括衡量人的活动的人口活动强度, 表征城市空间 要素的功能设施分布以及反映人的主观感受的街 景活力感知得分。

(1) 人口活动强度: 人口热力数据。人是活动 的缔造者与参与者, 规模化的人口数量是活动产生 的基础 ${ }^{[17]}$, 因此人口活动强度越高的地方, 城市活力 越高。人口活动强度可以用人口聚集度、就业集中 度、商业活动强度等指标来衡量。在众多指标中, 人口热力指标的数据相对容易获取, 且能准确动态 地反映人口活动强度。

(2)功能设施分布:POI数据。城市空间的表征 指标很多,包括人口、设施、夜间灯光等常见的城市 要素。在近期的研究中,POI数据被大量使用,它可 


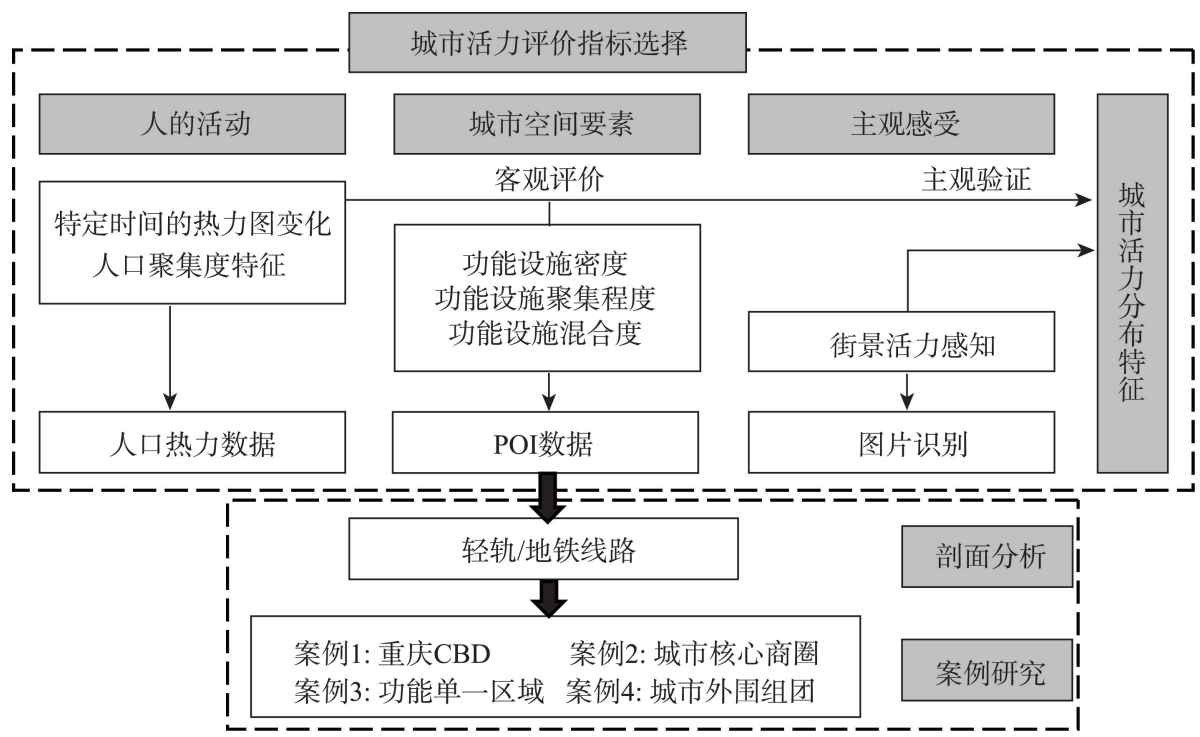

图 1 重庆主城区城市活力分析框架

Figure 1 Analytical framework of quantitative study on urban vitality in Chongqingcentralcity

以刻画城市要素在空间内的聚集程度和空间分布 特征, 弥补了传统数据的不足 ${ }^{[21]}$ 。已有研究表明, POI 混合度对城市活力的影响高于 POI密度 ${ }^{[18]}$,与城 市活力显著正相关,可以反映城市活力分布的空间 特征和城市功能设施完善程度,POI 混合度越高,城 市活力越高。

(3)街景活力感知: 街景图片数据。城市街道 与城市居民行为有着密切的联系 ${ }^{[2]}$ 。城市街景可以 通过大数据和计算机技术对城市外观进行虚拟评 估 ${ }^{[23]}$,通过训练模型来建立“街景图片与人的主观联 系”,对街道的活力、安全、压抑等方面进行评分,从 而为研究城市居民行为提供了一种新的视角。街 景图片评估出来的活力指数, 能相对直观地反映人 对街道活力的主观感受, 可以用于验证前面 2 个客 观维度的评估结果。

\subsection{3 指标计算}

(1) 基于核密度分析探究人口热力和 POI数据 聚集区

核密度分析工具用于计算要素在其周围邻域 中的密度。此工具既可计算点要素的密度, 也可计 算线要素的密度,近年来广泛运用于城市热点领域 的研究。本文通过ArcGIS 平台中的核密度分析工 具对人口热力数据和 POI 数据进行运算 ${ }^{[17]}$, 通过核 函数拟合地理要素在其所在空间及周围邻域中的
密度分布, 生成核密度分布图, 反映人口热力和不 同类型 POI 的空间聚集区和分布特征。

(2)基于自然断点法分类结果探究城市活力空 间分布特征

自然断点法用统计公式来确定属性值的自然 聚类, 尽量减少同一级中的差异、增加级间的差 异。基于 ArcGIS 软件的重分类工具, 利用自然断点 法对核密度分析结果进行分类,形成数据的自然裂 点, 从而明显地看出指标结果在空间上的高低值 分布。

(3)平均最近邻分析帮助识别不同类型 POI 聚 集程度

利用ArcGIS 中的“平均最近邻”工具进行分析, 比较目标点 $i$ 与相邻点的分布特征, 如果平均观测 距离小于预期, 则认为点要素具有聚集特征, 具体 用 $R$ 值(最邻近指数)表示, 该值越小, 聚集程度越 高。通过平均最近邻分析可以帮助探究不同类型 POI数据在空间上的聚集程度,得到高聚集区的分布 特征。

$$
\begin{gathered}
R=d_{i} / d_{\mathrm{e}} \\
d_{\mathrm{e}}=0.5 / \sqrt{N / A}
\end{gathered}
$$

式中: $d_{i}$ 为平均观测距离 $; d_{\mathrm{e}}$ 为预期平均距离 ${ }^{[2]} ; A$ 为研究区域面积; $N$ 为 $\mathrm{POI}$ 总数。

(4) 基于 POI 混合度探究不同区域的功能设施 
多样性程度。

POI 混合度用于表征城市功能设施的多样性。 混合度为 1 表示区域具有多功能性, 混合度为 0 , 则 区域具有单一功能。POI混合度与自然断点法和平 均最近邻方法结合, 探究不同区域的功能设施多样 性程度。

$$
\text { Diversity }=-\sum_{i=1}^{n}\left(p_{i} \times \ln p_{i}\right) \quad(i=1,2, \cdots, n)
$$

式中:Diversity 表示 POI 混合度; $n$ 表示 POI 的类别 数; $p_{i}$ 表示某类 $\mathrm{POI}$ 占所在街道 $\mathrm{POI}$ 总数的比例 ${ }^{[19]}$ 。

(5) 街景活力评价

街景活力评价的方法源于麻省理工实验室 (MIT Media Lab), 该实验室建立了 “Place Pulse 2.0 ”数据库, 收集网络志愿者对随机两张图片进行 安全、活力、无趣等方面的感知评价的比较结果。 2016年 10 月,该实验室共收集了 81630 名在线志愿 者的 117 万次图片比较结果。2016年 Dubey 等 ${ }^{[23]}$ 通 过训练模型和数据包对图片进行预测处理, 研究表 明, 通过机器学习获得全球尺度上的城市感知数据 是可行的。在此基础上,本文采用Keras 深度学习 库和深度残差网络 Resnet50, 对 50562 张百度街景 图片进行迁移学习训练, 获得重庆主城街景活力感 知得分数据。

\section{(6)剖面分析}

通过对城市剖面线沿程的人口和空间要素进 行观测, 可分析城市活力在空间上扩展和分布的特 征及规律。因此选择了在内环中心交汇, 地理位置 上向东南西北 4 个方向延伸的 $1 、 2 、 3 、 6$ 号地铁/轻轨 线作为剖面线,分析各项活力评价要素从市中心向 外围的空间变化情况。以解放碑 $\mathrm{CBD}$ 为中心点, 地
铁/轻轨站点为观测点进行剖面分析。剖面线的横 轴表示到解放碑的距离, 设置向北、向东方向为正 值, 向南、向西方面为负值。

\section{3 数据来源}

本文主要采用了 3 种类型的数据: 人口热力图、 POI 数据以及街景图片数据, 分别反映 3 类分析指 标: 人口活动强度、功能设施分布以及街景活力感 知,均与城市活力密切相关。

人口热力图来源于腾讯公司的地图服务窗口 (http://heat.qq.com/), 空间分辨率为 $25 \mathrm{~m}$ 。利用Python 程序抓取 2019 年 1 月 23 日 (工作日)和 3 月 17 日 (周末) 的人口热力数据, 获取时间间隔 $2 \mathrm{~h}$ 。人口 热力图记录了活跃的社交媒体登录信息及空间位 置信息, 可以实时准确地反映社交媒体用户的空间 聚集程度和分布情况。相比于每 10 年才能获取一 次的人口普查数据, 人口热力图更容易获取、时间 和空间分辨率更高。

POI 数据来源于高德在线地图数据 (http:// www.amap.com/), 对 2018 年 3 月抓取的数据进行篮 选处理之后, 共获得了 40.8 万条有效数据。POI数 据是地理系统中真实的点数据, 具有属性(名称、类 别等)和空间信息，包含公交站、商铺、地铁站、加油 站等多种类型。因其精度高、范围广、更新快、数据 量大等优点, 近年来广泛运用于城市空间结构分 析 ${ }^{[24,25]}$ 。在高德 POI 数据的 14 类分类体系基础上, 本文进一步概括为 6 个大类:生活服务类、公共服务 类、商务类、休闲娱乐类、居住类、金融保险类 ${ }^{[2]}$ (表1)。

街景图片来源于百度街景地图数据 (https:// map.baidu.com/), 2019年 5 月 17 日通过网络抓取

\section{表 1 重庆主城区POI 数据类型及比例}

Table 1 Types and proportion of point of interest (POI) in Chongqing central city

\begin{tabular}{llrr}
\hline \multicolumn{1}{c}{ 大类 } & \multicolumn{1}{c}{ 小类 } & 数量/个 & 比例/\% \\
\hline 生活服务类 & 餐饮服务、购物服务、生活类设施点 & 270170 & 66.09 \\
公共服务类 & 医疗保健服务、政府机构及社会团体、科教文化服务、交通设施服务 & 62339 & 15.25 \\
商务类 & 公司、企业 & 47105 & 11.52 \\
休闲娱乐类 & 运动场馆、高尔夫场馆及其附属设施、娱乐场所、度假疗养场所、休闲场 & 11721 & 2.87 \\
& 所、影剧院、公园广场、风景名胜 & 10121 & 2.48 \\
居住类 & 住宅小区、别墅、宿舍、其他居住相关楼宇 & 7312 & 1.79 \\
金融保险类 & 银行、自动提款机、保险公司、证券公司、财务公司 & & \\
\hline
\end{tabular}


2017年有效街景图片 50562 张。街景地图通过专业 相机将现实世界的空间场景捕捉下来, 利用软件将 多幅平面照片拼接合成,并模拟成三维空间的 360 度全景景观。考虑到谷歌街景地图数据难以获取 和腾讯街景地图覆盖不全, 本文选择百度街景地 图。百度街景每年采集一次, 能覆盖大部分城区, 具有空间分辨率高、交互性好、时效性强等优点, 被 广泛运用于城市街景研究。

\section{3 结果与分析}

\section{1 人口热力分析}

首先分析不同时段下人口活动强度的分布状 况。整体上看, 周末与工作日活动强度的空间分布 差异不大, 不同时段下热力峰值出现的区域也基本 相同。对出现热力峰值的区域进行分析, 可以将两 天内人口活动强度变化趋势划分为 3 个阶段: 上午 7 点一 9 点为上升期, 人口在这段时间迅速聚集; 上午 10 点一下午 7 点为稳定期, 该时段内人口活动强度 会出现一些波动，但总体维持在一定的规模强度; 下午 8 点之后为下降期, 人口活动强度显著降低。 上升期和下降期的时间点契合居民的上下班通勤 时间, 而稳定期的波动主要可能是由消费者和游客 的活动引起。除解放碑主中心外, 各副中心在周末 的人口热力大于工作日, 可能由不同类型地区居民 在周末和工作日的活动强度和节奏差异性引起。 由于周末上班族和学生的休息调整,集中在居民居 住地的休闲、娱乐活动增加, 而解放碑商务中心常 住人口相对较少, 可能导致周末人口流向各副中心， 解放碑主中心人口热力降低而各副中心增加。

再对两天的热力值进行均值化处理, 得到人口 活动强度核密度图 (图 2), 整体上看: 城市活力旺盛 的区域主要分布在内环内侧, 对应解放碑商务中 心、观音桥商圈、沙坪坝商圈、杨家坪商圈、南坪商 圈及石桥铺高新技术开发区。内环外侧的北碚、空 港、李家沱组团及茶园也表现出相对较高的城市活 力, 但对比内环内侧明显弱化。此外, 还可以看出 富有活力的各区域彼此独立, 规模相近。由于重庆 地形复杂, 在不同区域间的通勤成本尤其是时间成 本较高, 因此人口通常聚集在一定区域内, 当区域 内人口达到一定规模时更容易产生丰富的经济、社 会、文化等活动, 区域内便表现出较为旺盛的城市

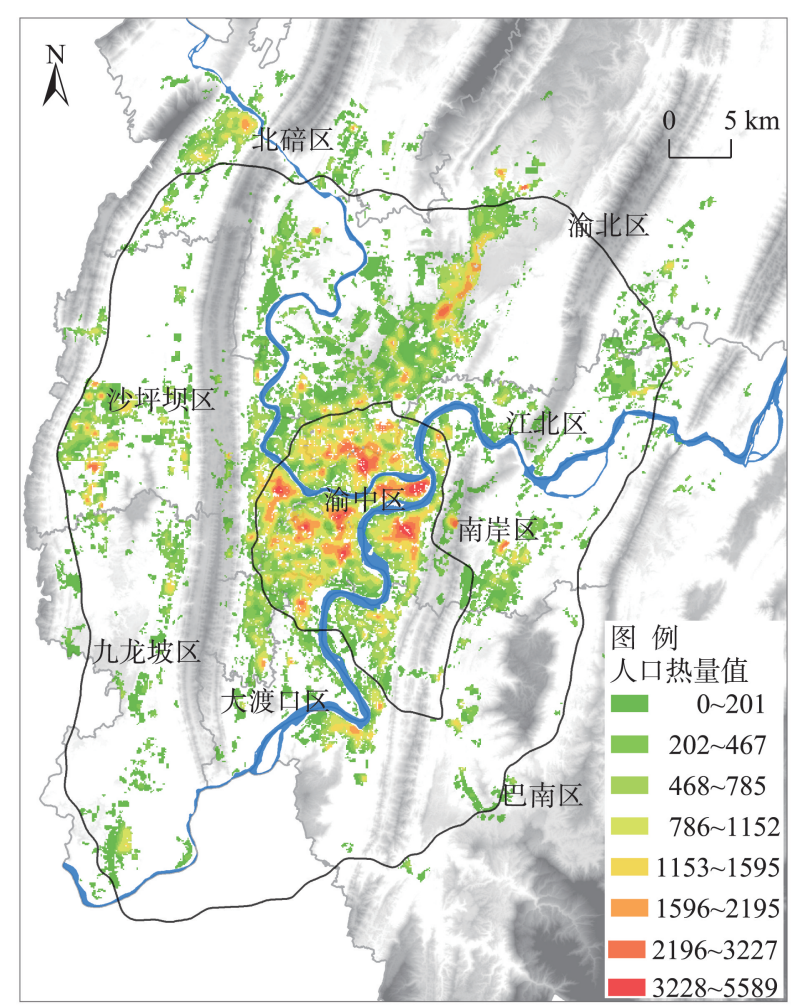

图 2 重庆市主城区人口热力值分布

Figure 2 Spatial distribution of population heat map in Chongqing central city

活力。同时,可以看出地形特征影响着城市空间结 构和人群活动的分布, 重庆主城区丘陵、低山分布 较多的中部和西北部聚集大量人口,主要围绕在两 江交汇的区域附近,西部和东南部受山脉阻隔, 人 口活力偏低。在山水格局的影响下, 富有城市活力 的区域集中在内环内侧并呈现出“多中心、组团式” 的分布特征。

\subsection{POI 设施分析}

城市功能设施是影响城市活力的重要因素 ${ }^{[26,27]}$, POI 的集中度和丰富度对城市活力的提升起到正向 促进的作用。首先对与居民生活密切度较高的商 务图3a、金融保险图3b、休闲娱乐图3c、生活服务图 $3 \mathrm{~d}$ 和公共服务图 $3 \mathrm{e}$ 类的 POI 核密度图进行分析。 不同类型 POI均呈现明显的聚集态势,但聚集区的 空间分布有所差异。5 类 POI 均在解放碑商务中 心、观音桥商圈、南坪商圈产生较高的聚集; 除金融 保险外,其余 4 类 POI 还在内环内侧的沙坪坝商圈、 杨家坪商圈及大渡口组团产生聚集; 此外, 休闲娱 乐、生活服务和公共服务类 POI 在内环外侧也出现 
小规模聚集, 主要分布在李家沱、空港、北碚、西永 等组团; 而大部分区域缺乏商务类与金融保险类功 能设施。

因此城市功能设施丰富, 更容易呈现出较高城 市活力的区域为: 解放碑商务中心、观音桥商圈、南 坪商圈、杨家坪商圈、沙坪坝商圈及内环外侧的李 家沱、空港、北碚、西永等组团。上述分析结果可以 从 5 类 POI 叠加后的核密度图 $3 \mathrm{f}$ 得到验证, 并且进 一步印证了重庆城市活力 “内环内侧明显高于外 侧”及“多中心、组团式”的分布特征。

城市功能设施的完善对人口活动的多样性有 着重要的支撑作用,直接影响区域内城市活力的水 平,一般情况下, POI 混合度越高, 城市活力越旺 盛。POI 混合度分布图 (图 4)显示: 整体上,POI 混 合度表征下的城市活力空间分布特征与人口活动 强度相似, 同时与 POI 高聚集区域的空间叠合性较
高。城市活力呈现多中心的分布特征,活力较高的 不同区域彼此独立, 规模大小相近, 区域内均有地 铁/轻轨线路分布。在内环内侧,城市活力整体水平 较高, 面积占比大, 对应解放碑商务中心、观音桥商 圈、南坪商圈、大坪商圈、杨家坪商圈、沙坪坝商圈、 两路口及大渡口组团; 内环外侧城市活力锐减, 主 要分布在北碚、空港、西永、西彭组团及茶园副中心。

对比 POI 混合度与人口热力, 发现 POI混合度 聚集区的面积更大, 聚集程度整体上略高于人口热 力, 局部以北碚、空港、西永、西彭组团最为明显。 原因可能是主城区内大部分区域还在进一步吸纳 人口。区域内的公共服务及生活服务等设施的建 设规模在满足当前人口需求的情况下,仍有一定的 弹性空间以满足流动人口的需求, 从而导致区域内 POI 混合度的聚集度高于人口热力。而在北碚、西 永等组团,这种现象可能是由人口迁移的滞后性引
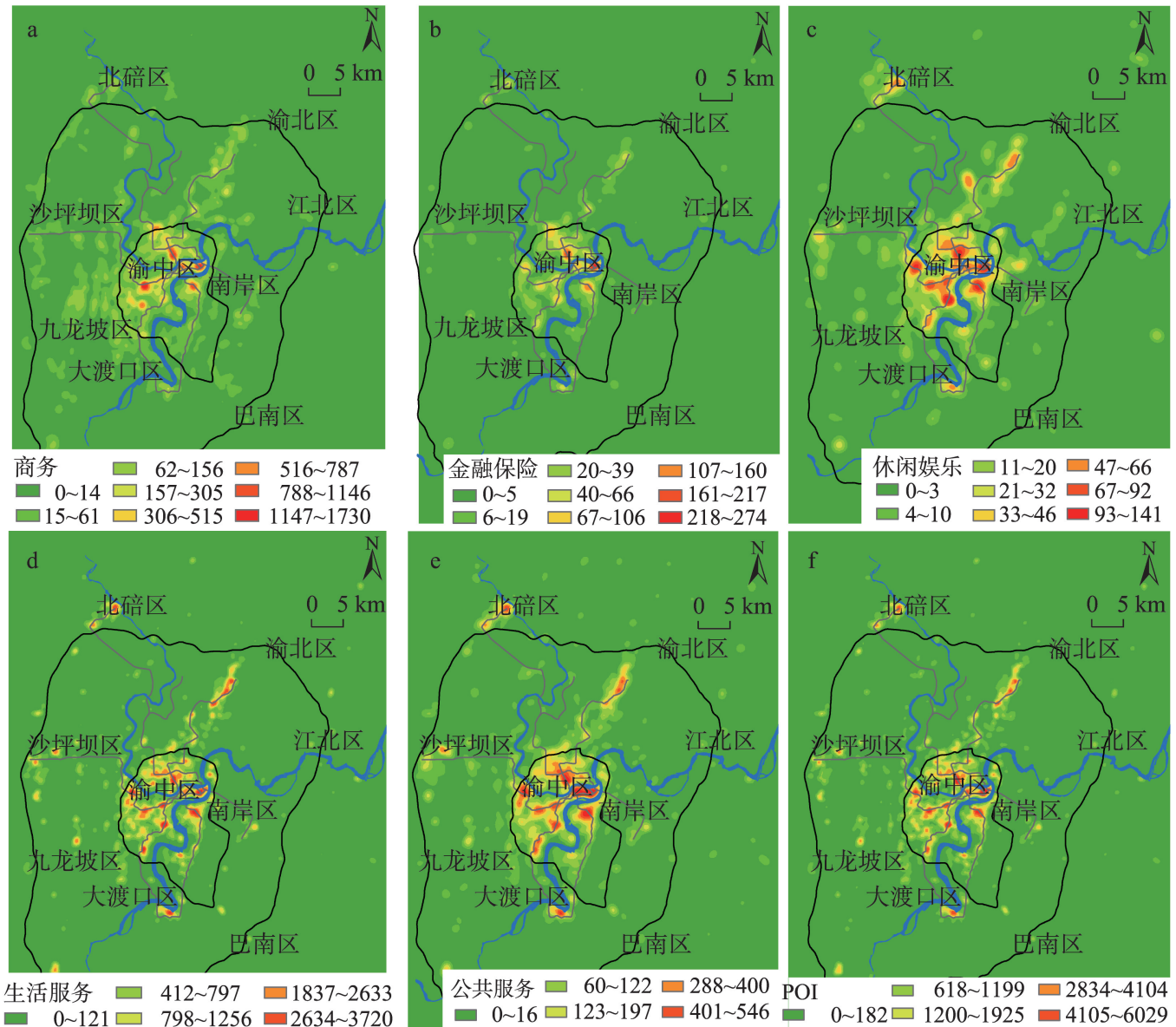

公共服务 $\square$ 60 122 $\square 288 \sim 400$ POI

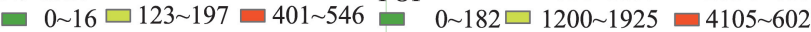

$\square 122 \sim 411 \square$ 1257 1836 $\square 3721 \sim 6160$

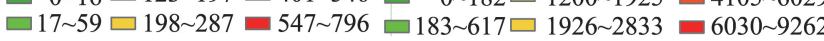

图 3 重庆市主城区不同类型POI核密度分布

Figure 3 Kernel density of point of interest (POI) in Chongqing central city 


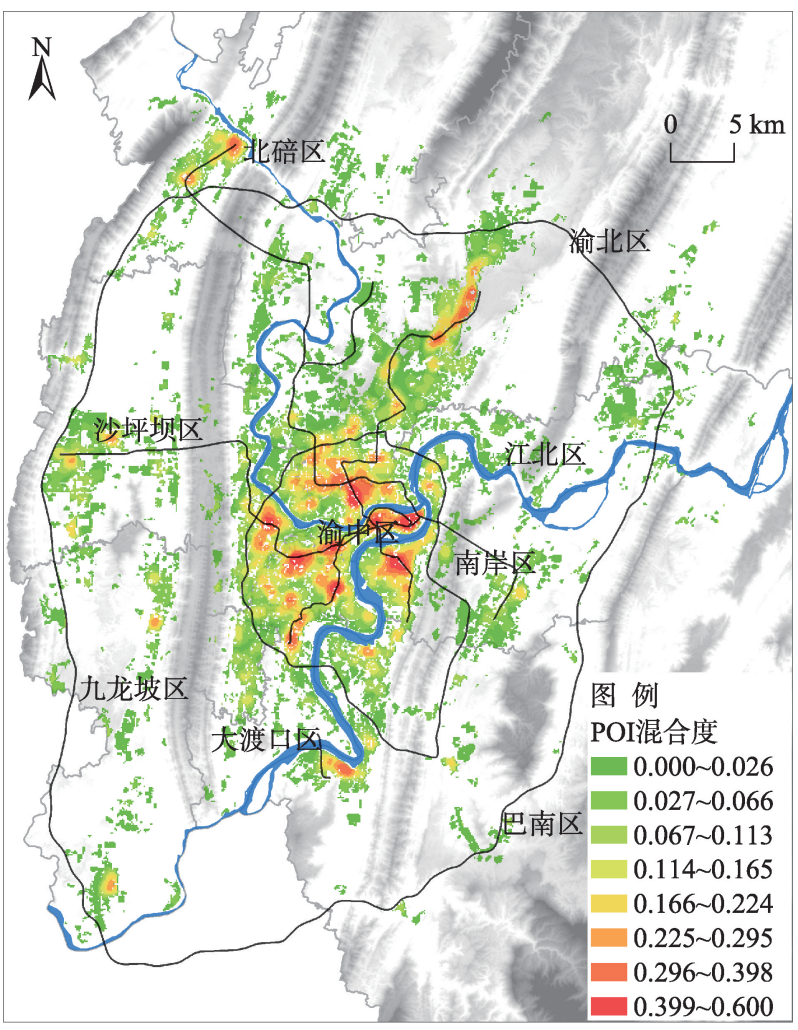

图 4 重庆主城区 POI 混合度分布

Figure 4 Spatial distribution of point of interest (POI) mix in Chongqing central city

起的, 这些组团位于内环外侧, 是城市近年来规划 发展的新区。在政府规划的大力支持下, 空间要素 率先得到发展, 城市功能设施得到完善, 尤其是教 育和居住功能在短期内得到大幅提升, 但人口的迁 移需要相对较长的时间, 因此目前的城市活力还处 于较低水平。

\section{3 剖面线分析}

近年来, 随着重庆地铁/轻轨的大力发展, 已覆 盖内环内侧大部分区域,并延伸至外侧较广范围, 因此将地铁/轻轨线路作为剖面线对城市活力的分 布进行分析。结果(图 5)表明:整体上,POI混合度 与人口热力值有相同的变化趋势; 从市中心到外围 城市活力逐渐降低, 在局部区域出现了活力较高的 次高峰; 在较小范围内, 距离市中心越近, 城市活力 越高, 当研究范围扩大到一定程度时, 这种影响由 邻近的城市商圈代替。城市活力高的站点主要分 布在解放碑主中心、城市副中心及城市大型商圈附 近, 这些区域功能设施的集中度和丰富度能满足人 口生活的多样性需求, 吸引大量的人口聚集, 产生
丰富的社会、经济、文化等活动, 呈现出较高的城市 活力。内环外侧城市活力锐减, 只有尖顶坡和北碚 2 个站点城市活力表现相对较好, 分别对应西永和 北碚组团,这两个组团内的教育和居住功能较为完 善, 在内环外侧聚集了一定的人口, 呈现出较高的 城市活力。

\section{4 街景活力感知分析}

街景活力感知从主观的维度反映城市活力的 分布特征。图 6 是街景活力感知得分图, 由图可知, 分值高的区域面积大且相对分散,说明重庆主城城 市活力的整体水平较高。内环内侧的街景活力总 体高于内环外侧, 尤其是解放碑主中心及沙坪坝、 杨家坪、观音桥、南坪副中心的活力相对较高,整体 上与人口热力、POI混合度评价结果一致, 呈现“内 环内侧高、外侧低”及“多中心”分布特征。高速公 路沿线区域的活力感知明显低于主城核心区域,更 为明显地说明了江河阻隔和道路切割对城市活力 的影响。机场周边的整体活力偏低,其原因是机场 位于内环外侧, 远离商圈, 城市功能单一, 难以满足 居民生活多样性的需求, 区域内的活动主要由机场 乘客引起,难以营造旺盛的城市活力。

\section{5 典型案例分析}

选择 4 个案例,计算街景活力感知得分 (表 2 ), 对城市活力进行评价的结果与前 2 个维度评价结果 是否一致进行验证, 并讨论 POI 混合度和人口活动 强度对城市活力的影响。案例 $1 、 2 、 3$ 位于内环内 侧, 案例4位于外侧(图 7)。

案例 1 : 解放碑是重庆的中央商务区,多年来, 凭借其独特的历史背景和区位优势不断发展, 成为 重庆最具活力的区域。首先, 区域内成熟的配套设 施和丰富的商业资源对活力的贡献功不可没,作为 重庆市的中央商务区, 解放碑提供了大量的工作岗 位和商业资源, 聚集大量办公和消费人群,保证了 其持续旺盛的活力。其次,解放碑完善的步行系 统、便利的公共设施大大提升了街道空间品质, 为 解放碑的活力营造起到了推动的作用。此外,解放 碑作为重庆旅游地标, 附近旅游资源密集, 在网络 宣传的作用下, 旅游效益显著升级, 吸引了大量游 客,成为解放碑重要的活力来源。

案例 2 : 石桥铺本身拥有悠久的历史文化,开发 

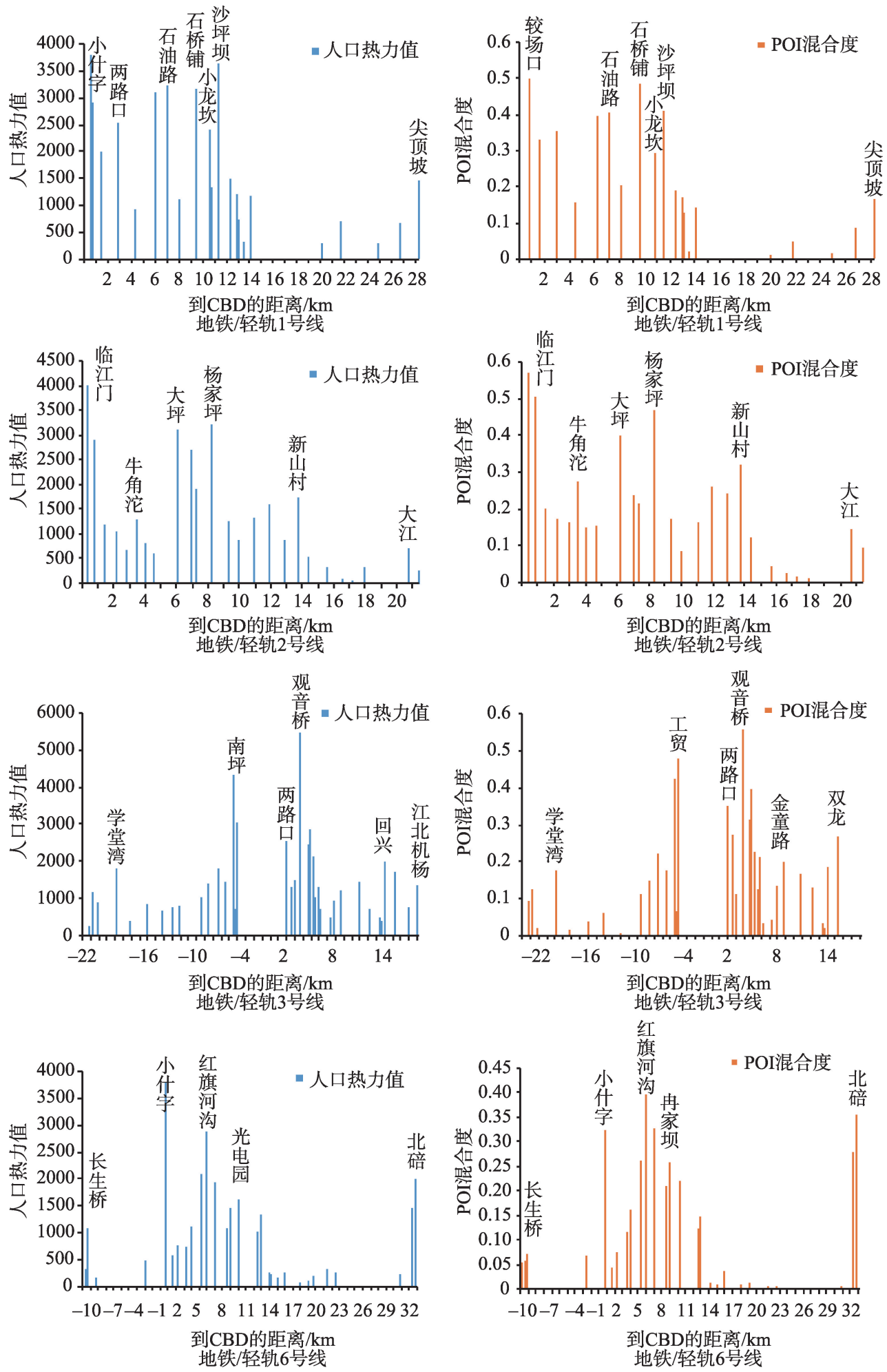

图 5 沿剖面线的人口热力值与 POI 混合度分布

Figure 5 Distribution of population heat value and point of interest (POI) mixing degree along the profile line

建设已久,作为重庆高新区核心区域、IT数码中心， 曾是重庆商业活动的重要聚集地。但随着城市的 发展, 石桥铺商圈业态单一的问题日益凸显, 消费
者被相邻商圈分流，区域发展动力殆尽。2014年, 高新区依托轨道交通的优势,对石桥铺商圈业态进 行调整规划, 强调多功能和复合型商圈的打造以及 


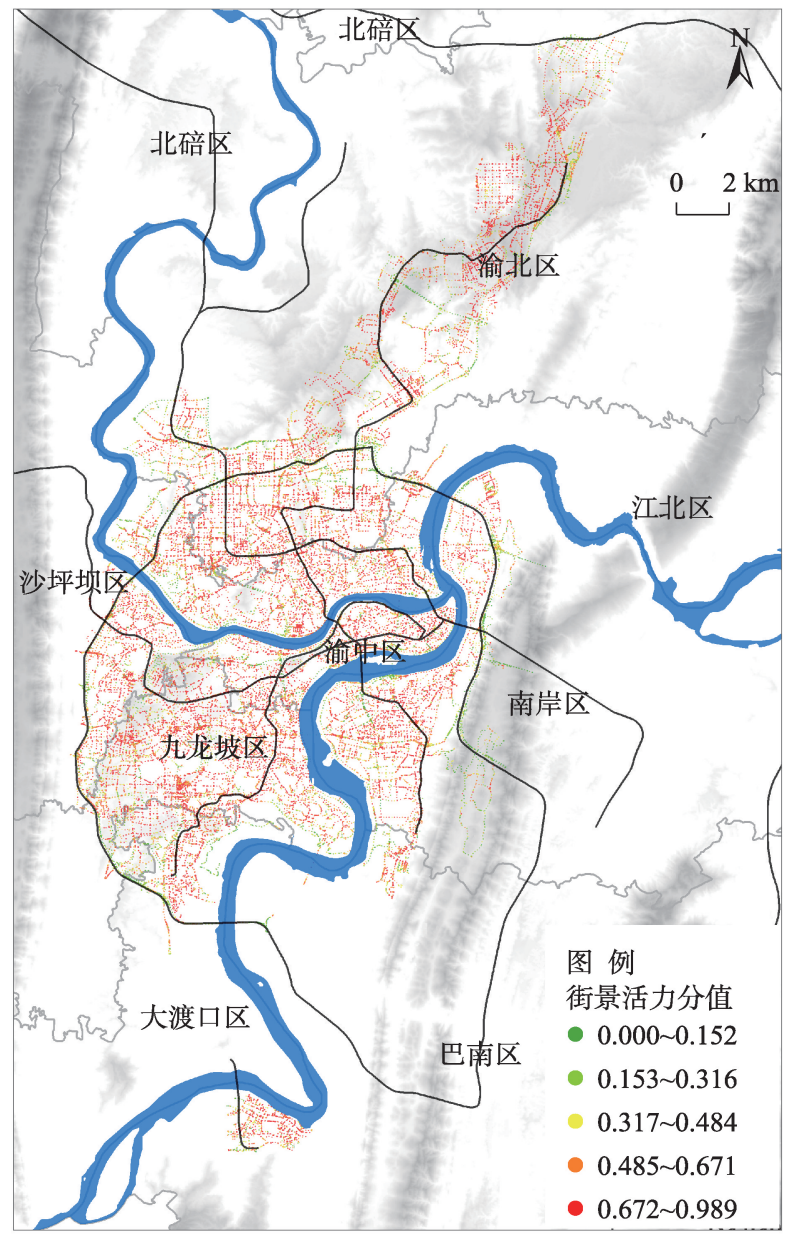

图 6 街景活力感知得分分布

Figure 6 Spatial distribution of perception scores of streetscape vitality
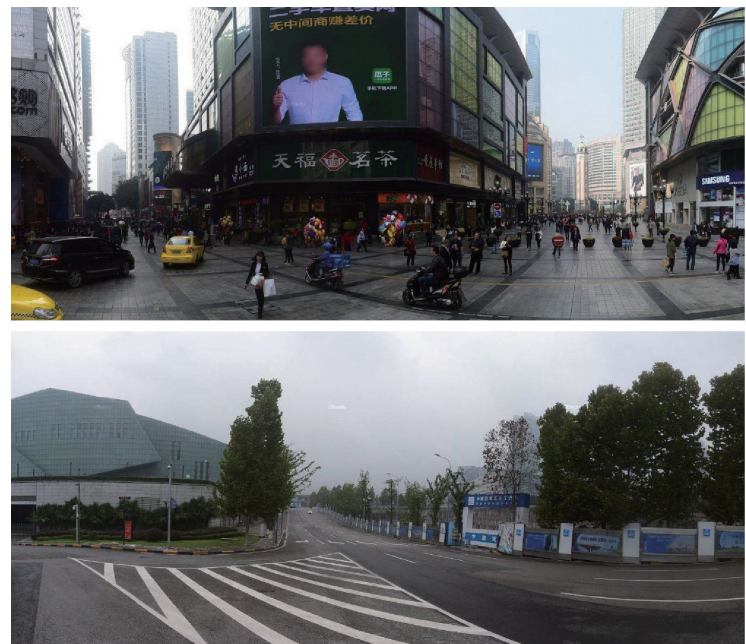

表 2 典型案例的城市活力分值

Table 2 City vitality score of typical sites

\begin{tabular}{cccc}
\hline 案例 & 人口热力 & POI混合度 & 街景活力感知得分 \\
\hline 1.解放碑 & 4572.12 & 0.60 & 0.92 \\
2.石桥铺 & 3532.50 & 0.49 & 0.74 \\
3.大剧院 & 287.61 & 0.02 & 0.36 \\
4.回兴 & 2248.31 & 0.22 & 0.58 \\
\hline
\end{tabular}

周边配套设施的完善。功能设施的不断完善使石 桥铺的商业辐射能力大大提升,成为重庆的核心商 圈之一, 对人口的聚集能力显著增强, 城市活力重 新恢复较高水平。

案例 3 : 重庆大剧院是重庆市规划的重要文化 项目设施之一,位于 $\mathrm{CBD}$ 核心区内与朝天门隔江相 望, 是两江交汇处最重要的景观建筑之一, 地理位 置优越但城市功能单一, 主要接待国内外大型艺术 团的表演活动, 能吸引一定的演出者和观众, 但由 于缺乏与人口活动密切相关的生活服务设施, 难以 满足人口活动的多样性需求, 演出结束后这部分人 口流向其他区域。相比之下, 与大剧院隔江遥相呼 应的南山风景区有多元化的旅游资源, 自然植物 园、野外休闲区以及“日观市容市貌,夜览山城夜 景”的一棵树观景园，还有配套的特色餐饮和酒店 等服务设施, 对本地和外地的游客都有较强的吸引 力, 较高的 POI混合度支撑了丰富的旅游休闲活动, 营造了区域较高的城市活力。
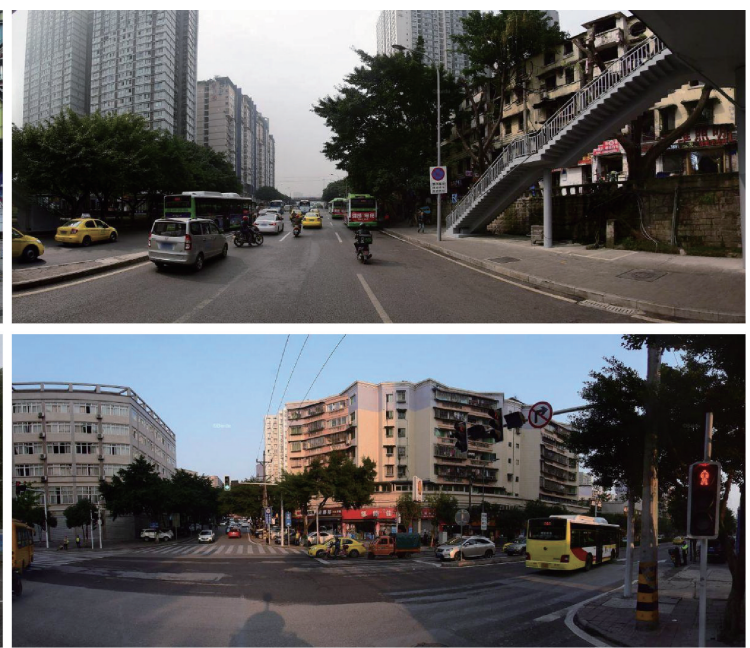

图 7 典型案例的街景图

Figure 7 Street view of typical sites

(注:左上为解放碑;右上为石桥铺;左下为大剧院;右下为回兴) 
案例 4: 回兴是通过提升 POI 混合度来营造城 市活力的典型区域。回兴位于内环外侧, 受到城市 主副中心的带动效益较弱, 活力本来偏低。但 2013 年以来, 经过创新创业发展、引进了科技产业、现代 农业、两路工业园区, 同时, 区域内配套设施逐渐成 熟, 教育、医疗、公园、商业一应俱全, POI混合度不 断提升, 实现了由农村到镇到城区的转变。在内环 外侧吸引了一定规模的人口, 区域内城市活力得到 较大幅度的提升。

\section{4 讨论}

\section{1 基于大数据的城市活力研究方法}

本文突破了传统调查问卷和专家打分的局限 性, 基于大数据定量探讨城市活力的分布特征, 并 提出了人口热力、POI混合度、街景活力感知 3 个维 度组成的城市活力评价框架, 这为相关研究提供了 新的思路。人口热力图、POI数据等大数据具有 “大 范围、高精度” 的特点, 相比于传统问卷调查或街道 尺度的样点观测, 研究样本更多、尺度更大; 相较于 人口普查、经济普查等常规数据, 更新速度更快、获 取成本更低, 大幅度提升城市活力研究的准确性和 时效性,因而能更好地表征城市活力。还采用基于 机器学习和街景数据的城市活力感知数据, 引人人 对活力的主观感受这一维度, 改变传统研究侧重于 “物质空间和场所” 的现象, 促进城市活力研究更加 注重 “以人为本” ${ }^{[28]}$ 。尽管已有学者广泛利用图片类 数据进行城市研究, 但采用传统调查问卷、实地调 研、专家打分方法对海量图片进行处理 ${ }^{[29-31]}$, 需要消 耗大量时间和资源, 难以拓展到大范围的研究。本 文在前人的基础上, 通过机器学习, 提升了研究效 率, 更加科学、全面, 能为相关城市研究提供借鉴。

\section{2 平原城市和山地城市的活力特征比较}

研究发现,重庆主城区的城市活力呈现明显的 “多中心、组团式” 分布特征, 这与平原城市的“圈 层”结构形成鲜明的对比。以成渝经济区的成都为 例, 成都的城市活力在二环内较高、二环外锐减, 呈 现典型的 “圈层” 结构分布 ${ }^{[18]}$ 。相比之下, 重庆主城 区被缙云山、中梁山、铜锣山和明月山分割, 同时受 到长江和嘉陵江的阻断形成 “四山夹两江” 的地形 特征。在地形条件的限制和资源集约的驱动下, 多 中心结构被不断强化, 历年来城市规划也多顺应这
一空间结构,城市要素和人口在各城市中心聚集, 塑造了城市活力的分布特征。虽然重庆主城区城 市活力也有内环高、外环明显弱化的特点, 但没有 明显的圈层分布特征, 多中心、组团式的特点更加 显著。

此外, 分析结果还发现, 重庆多中心布局相对 均衡, 不同中心之间彼此独立、规模相似、发展程度 相近,这与平原城市“主强副弱”的发展模式形成对 照。有学者对上海城市活力的分布特征和内在机 制展开研究, 发现上海活力热点在空间维度上高度 聚集于城市中心, 活力冷点散布在周围, 活力强度 由内至外圈层式衰减变弱 ${ }^{[32]}$ 的特征。而重庆副中心 及外围组团的城市活力相对较高, 能有效避免主中 心资源高度集中, 副中心资源弱化、人口聚集能力 差而导致的区域发展失衡和城市活力消解等问题, 同时有效缓解主中心的交通和职住压力。

\section{5 结论与政策建议}

\section{1 结论}

本文从人口热力、POI混合度、街景活力感知得 分 3 个维度对重庆主城区的城市活力进行了定量分 析, 研究发现:

(1) 从人口分布、设施分布及活力感知 3 个不同 维度评价出来的城市活力, 在总体空间格局上具有 相似性。城市活力旺盛的区域主要分布在内环内 侧的解放碑主中心及沙坪坝、杨家坪、观音桥、南 坪、茶园、西永等副中心; 城市内环外侧的城市活力 明显弱化,对应北碚、空港、茶园及李家沱组团。

(2)部分区域 POI 混合度测度下的城市活力略 高于人口热力, 以北碚、空港、西永和西彭组团最为 明显。差异明显的区域均为重庆近年来开发建设 的城市新区, 目前, 这些区域还在进一步吸纳人口 的进程中。在其城市活力的营造过程中, 功能设施 的建设先于人口的聚集, 导致评价结果的局部 差异。

(3)研究还发现,重庆主城区城市活力分布具 有多中心的显著特征,富有活力各区域“彼此独立、 规模相似”,这与重庆主城区“多中心、组团式”的格 局相契合。

(4)将城市活力的空间分布与地形图相结合分 
析, 发现地形特征影响着城市空间结构和人群活动 的分布, 进而在一定程度上影响了城市活力格局的 塑造。

\section{2 政策建议}

本文对重庆市的城市活力提升主要有以下 启示：

研究发现, 重庆主城区城市活力整体较高, 内 环内侧的解放碑、观音桥等主/副中心富有城市活 力, 城市活力缺乏的区域主要为各城市中心的周边 区域与内环外围的茶园副中心及北碚、空港、西永 等组团。各城市中心的周边区域由于人口高度聚 集于城市中心而发展缓慢, 城市活力缺失。这些区 域提升城市活力的首要任务是提升与人们日常生 活相关度最高的生活服务和公共服务类要素的投 人, 同时提高交通可达性和易达性, 通过城市中心 的带动效益, 有机地吸纳人口。在满足人口居住、 生活需求的基础上进一步引人教育、医疗、休闲娱 乐等配套设施, 吸引更多人口, 在区域自身不断发 展的同时缓解城市中心的职住压力和交通拥堵 问题。

外围各组团活力低的主要原因是区域内城市 功能单一, 以教育、居住或工业为主,受重庆地形的 限制, 通勤成本较高, 难以与内侧区域形成联动发 展。提升功能密度和混合度是改善这些区域的最 佳选择,加大区域内城市要素和资源的投人,以满 足人口活动的多样性需求。考虑到人类活动是城 市活力产生的基础和源泉,而街道空间品质又是吸 引人类活动的主要因素,所以应在完善区域功能设 施的基础上,塑造良好的街道空间品质来营造更高 的城市活力。

本文基于大数据对重庆城市活力进行客观识 别和评价, 为城市活力定量研究提供了一种新的思 路和视角, 使城市活力的定量分析更加准确和高 效。针对山地城市的研究,也弥补了已有文献在山 地城市活力研究方面的不足。然而, 由于数据获取 的限制, 本文采用的人口热力图并不能直接反映人 口数量, 只能反映人口分布的相对聚集程度; 街景 地图覆盖了主城区大部分区域, 但外围的一些副中 心、组团还缺乏数据, 以上不足之处有待在今后进 一步完善。

\section{参考文献(References):}

[1] 张程远, 张淦, 周海瑶. 基于多元大数据的城市活力空间分析与 影响机制研究: 以杭州中心城区为例 [J]. 建筑与文化, 2017, (9): 183-187. [Zhang C Y, Zhang G, Zhou H Y. The analysis and influence mechanism research of urban vigorous space based on multiple big data: A case study on the partial area of central Hangzhou[J]. Architecture \& Culture, 2017, (9): 183-187.]

[2] 张景奇, 娄成武. 中美城市蔓延特征差异对比及对中国蔓延治 理的启示 [J]. 资源科学, 2014, 36(10): 2131-2139. [Zhang J Q, Lou C W. New ideas on Chinese urban sprawl governance by contrasting Chinese and American urban sprawl[J]. Resources Science, 2014, 36(10): 2131-2139.]

[3] 张耀宇, 陈利根, 宋璐怡. 中国城市用地扩张驱动机制的差异性 研究[J]. 资源科学, 2016, 38(1): 30-40. [Zhang Y Y, Chen L G, Song L Y. Differences in driving-force mechanisms in urban land expansion in China[J]. Resources Science, 2016, 38(1): 30-40.]

[4] 童陆亿, 胡守庚. 中国主要城市建设用地扩张特征[J]. 资源科 学, 2016, 38(1): 50-61. [Tong L Y, Hu S G. Characterizations of urban sprawl in major Chinese cities[J]. Resources Science, 2016, 38(1): 50-61.]

[ 5] 董祚继. 新时代国土空间规划的十大关系[J]. 资源科学, 2019, 41(9): 1589-1599. [Dong Z J. Ten relations of territorial planning in the new era[J]. Resources Science, 2019, 41(9): 1589-1599.]

[6] 罗桑扎西, 甄峰. 基于手机数据的城市公共空间活力评价方法 研究: 以南京市公园为例[J]. 地理研究, 2019, 38(7): 15941608. [Luo S Z X, Zhen F. How to evaluate public space vitality based on mobile phone data: An empirical analysis of Nanjing's parks[J]. Geographical Research, 2019, 38(7): 1594-1608.]

[7] 王勇, 邹晴晴, 李广斌. 基于活力特征分析的城市安置社区公共 空间研究: 以苏州城区 6 个安置社区为例[J]. 地理科学, 2018, 38(5): 747-754. [Wang Y, Zou Q Q, Li G B. Public space construction of urban resettlement community based on analysis of vitality characteristics: Taking the 6 resettlement communities of Suzhou as examples[J]. Scientia Geographica Sinica, 2018, 38(5): 747-754.]

[8] Jacobs J. The Death and Life of Great American Cities[M]. New York: Random House Press, 1961

[9] 凯文・林奇. 城市印象[M]. 北京: 华夏出版社, 2003. [Lynch K. The Image of City[M]. Beijing: Huaxia Publishing House, 2003.]

[10] 杨-盖尔. 交往与空间[M]. 何人可, 译. 北京: 中国建筑工业出版 社, 1992. [Gehl J. Life Between Buildings[M]. He R K, Trans. Beijing: China Architecture \& Building Press, 1992.]

[11] 徐否青, 康琦. 商业街的空间与界面特征对步行者停留活动的 影响: 以上海市南京西路为例[J]. 城市规划学刊, 2014, (3): 104-111. [Xu L Q, Kang Q. The relationship between pedestrian behaviors and the spatial features along the ground-floor commer- 
cial street: The case of West Nanjing Road in Shanghai[J]. Urban Planning Forum, 2014, (3): 104-111.]

[12] 魏川登, 潘海啸. 轨道站点周边地区步行环境评价: 以上海市静 安寺地铁站为例[J]. 交通工程, 2017, 17(3): 58-64. [Wei C D, Pan H X. Evaluation of walking environment around railway station: Case study on Jing' an temple station of Shanghai[J]. Journal of Transportation Engineering, 2017, 17(3): 58-64.]

[13] 高磊, 黄家宽, 姜晓许, 等. 基于个体移动数据的城市活力实证 研究[J]. 科技创新与生产力, 2018, (5): 64-67. [Gao L, Huang J K, Jiang X X, et al. Empirical research on urban vitality based on individual mobile data[J]. Sci-tech Innovation and Productivity, 2018, (5): 64-67.]

[14] Kim Y L. Seoul's Wi-Fi hotspots: Wi-Fi access points as an indicator of urban vitality[J]. Computers Environment \& Urban Systems, 2018, 72: 13-24.

[15] Oppio A, Bottero M, Arcidicacon A. Assessing urban quality: A proposal for a MCDA evaluation framework[J]. Annals of Operations Research, 2018, (1): 1-18.

[16] 罗克乾, 沈中伟. 基于空间句法的城市地下空间活力研究: 以成 都市轨道交通站点接驳的地下空间为例[J]. 南方建筑, 2019, (4): 116-121. [Luo K Q, Shen Z W. Research on urban underground space vitality based on space syntax: A case study on the underground space connected by Metro Stations in Chengdu City [J]. South Architecture, 2019, (4): 116-121.]

[17] 刘云舒, 赵鹏军, 梁进社. 基于位置服务数据的城市活力研究: 以北京市六环内区域为例[J]. 地域研究与开发, 2018, 37(6): 64-87. [Liu Y S, Zhao P J, Liang J S. Study on urban vitality based on LBS data: A case of Beijing within 6th Ring Road[J]. Areal Research and Development, 2018, 37(6): 64-87.]

[18] 龙瀛, 周垠. 街道活力的量化评价及影响因素分析: 以成都为例 [J]. 新建筑, 2016, (1): 52-57. [Long Y, Zhou Y. Quantitative evaluation on street vibrancy and its impact factors: A case study of Chengdu[J]. New Architecture, 2016, (1): 52-57.]

[19] 郝新华, 龙瀛, 石沝, 等. 北京街道活力: 测度、影响因素与规划 设计启示 $[J]$. 上海城市规划, 2016, (3): 37-45. [Hao X H, Long Y, Shi M, et al. Street vibrancy of Beijing: Measurement, impact factors and design implication[J]. Shanghai Urban Planning Review, 2016, (3): 37-45.]

[20] 庄良, 叶超, 马卫, 等. 中国城镇化进程中新区的空间生产及其 演化逻辑[J]. 地理学报, 2019, 74(8): 1548-1562. [Zhuang L, Ye C, Ma W, et al. Production of space and developmental logic of New Urban Districts in China[J]. Acta Geographica Sinica, 2019, 74(8): 1548-1562.]

[21] 段亚明, 刘勇, 刘秀华, 等. 基于 POI大数据的重庆主城区多中 心识别[J]. 自然资源学报, 2018, 33(5): 788-800. [Duan Y M, Liu Y, Liu X H, et al. Identification of polycentric urban structure of central Chongqing using points of interest big data[J]. Journal of
Natural Resources, 2018, 33(5): 788-800.]

[22] Raskar R, Naik N D, Philipoom J D, et al. Streetscore: Predicting the Perceived Safety of One Million Streetscapes[C]. Columbus: Proceedings of the IEEE Conference on Computer Vision \& Pattern Recognition Workshops, 2014.

[23] Dubey A, Naik N, Parikh D, et al. Deep Learning the City: Quantifying Urban Perception at a Global Scale[R]. Amsterdam: European Conference on Computer Vision, 2016.

[24] 郭洁, 吕永强, 沈体雁. 基于点模式分析的城市空间结构研究: 以北京都市区为例[J]. 经济地理, 2015, 35(8): 68-74. [Guo J, LYu Y Q, Shen T Y. Urban spatial structure based on point pattern analysis: Taking Beijing metropolitan area as a case[J]. Economic Geography, 2015, 35(8): 68-74.]

[25] 吴康敏, 张虹鸥, 王洋, 等. 广州市多类型商业中心识别与空间 模式[J]. 地理科学进展, 2016, 35(8): 963-974. [Wu K M, Zhang H O, Wang Y, et al. Identify of the multiple types of commercial center in Guangzhou and its spatial pattern[J]. Progress in Geography, 2016, 35(8): 963-974.]

[26] Montgomery J. Making a city: Urbanity, vitality and urban design [J]. Journal of Urban Design, 1998, 3(1): 93-116.

[27] Koster H, Rouwendal J. The impact of mix land use on residential property values[J]. Journal of Regional Science, 2012, 52(5): 733-761.

[28] 龙瀛, 周垠. 图片城市主义: 人本尺度城市形态研究的新思路 [J]. 规划师, 2017, 33(2): 54-60. [Long Y, Zhou Y. Pictorial urbanism: A new approach for human scale urban morphology study[J]. Planners, 2017, 33(2): 54-60.]

[29] 李智, 龙瀛. 基于动态街景图片识别的收缩城市街道空间品质 变化分析: 以齐齐哈尔为例[J]. 城市建筑, 2018, (6): 21-25. [Li Z, Long Y. An analysis on variation of quality of street space in shrinking cities based on dynamic street view pictures recognition: A case study of Qiqihar[J]. Urbanism and Architecture, 2018, (6): 21-25.]

[30] 李诗卉, 杨卓, 梁潇, 等. 东四历史街区: 基于多时相街景图片的 街道空间品质测度[J]. 北京规划建设, 2016, (6): 39-48. [Li S H, Yang Z, Liang X, et al. Four historical districts: Measurement of street space quality based on multi temporal street view pictures [J]. Beijing Planning Review, 2016, (6): 39-48.]

[31] 刘星, 盛强, 杨振盛. 街景地图对街道活力分析的适用性研究 [J]. 城市建筑, 2018, (6): 40-43. [Liu X, Sheng Q, Yang Z S. A feasibility study of streets view map on street quality evaluation[J]. Urbanism and Architecture, 2018, (6): 40-43.]

[32] 王玉玩. 基于手机信令数据的上海中心城区城市空间活力特征 评价及内在机制研究[D]. 南京: 东南大学, 2017. [Wang Y Z. Research on Urban Vitality Characteristic Evaluation and Internal Mechanism of Shanghai Central City based on Mobile Phone Signaling Data[D]. Nanjing: Southeast University, 2017.] 


\title{
Vitality assessment of mountainous cities based on multi-source data: A case of Chongqing Municipality, China
}

\author{
MING Yujia ${ }^{1}$, LIU Yong ${ }^{1}$, ZHOU Jiasong ${ }^{2}$ \\ (1. School of Construction Management and Real Estate, Chongqing University, Chongqing 400044, China; \\ 2. Land Improvement Center of Sichuan Province, Chengdu 610000, China)
}

\begin{abstract}
With the rapid urbanization in China, the emergence of urban diseases has led to the decline of urban quality and urban vitality. Urban vitality provides a new perspective for the study of urban issues. The use of big data provides an accurate and efficient means for the study of urban vitality. Based on the dimensions of population heat map and point of interest (POI) distribution, this study quantitatively evaluated the urban vitality in the central city of Chongqing, and validated the derived vitality values based on the score of street view perception. The results show that the spatial distribution of urban vitality in Chongqing is characterized by multi-center distribution, which is consistent with its multi-center and clustered urban structure. The urban vitality evaluated by three indicators is similar in spatial pattern. It shows that the areas with high urban vitality are mainly located in the inner ring of Chongqing, especially in the main center of Jiefangbei and subcenters, such as Shapingba, Yangjiaping, Guanyinqiao, and Nanping. The areas with high urban vitality correspond to the sub-centers of Chayuan and Xiyong outside the inner ring. This result is also consistent with the score of street view perception. The study confirms that the evaluation of urban vitality based on big data can compensate for the deficiency of traditional qualitative analysis methods and provide a new way of thinking and perspective for the quantitative study of urban vitality. The study of a mountainous city also addresses the deficiency of the existing studies on mountain city vitality and can help policy making in spatial planning.
\end{abstract}

Key words: urban vitality; heat map; point of interest (POI); perception of urban environment; Chongqing Municipality 